\title{
Mid-Term Results of Large-Diameter Ceramic-Bearing Monoblock Acetabular Components in THA.
}

\author{
Valeriy Murylev ( $\nabla$ nmuril@yandex.ru ) \\ Sechenov University \\ Pavel Elizarov \\ Sechenov University \\ Alexey Muzychenkov \\ Sechenov University \\ Yaroslav Rukin \\ Sechenov University \\ Grigoriy Kukovenko \\ Sechenov University \\ Semen Alexeev \\ S.P. Botkin Moscow City Clinical Hospital \\ Michail Elizarov \\ Sechenov University
}

\section{Research Article}

Keywords: primary THA, CoC friction pairs, cementless hip arthroplasty, squeak, large diameter ceramic bearing monoblock

Posted Date: February 15th, 2021

DOI: https://doi.org/10.21203/rs.3.rs-152127/v1

License: (c) (i) This work is licensed under a Creative Commons Attribution 4.0 International License. Read Full License 


\section{Abstract}

Introduction: Durability and better function are the challenging issue of any tribological pair. Ceramic on Ceramic (CoC) friction pairs should provide long-term wear and functional results.

Objectives: To evaluate the mid-term results of using the monoblock acetabular system Maxera Cup (Zimmer Biomet) in cementless total hip arthroplasty.

Materials and Methods: We evaluated the THA with Monoblock Maxera Cup (Zimmer Biomet) acetabular system in 93 patients. The mean follow-up was 4 years ( $49.5 \pm 11.7$ months). All 103 total hip arthroplasty cases in 93 patients were divided into 3 groups according to the diameters of $\mathrm{CoC}$ friction pairs $(40,44,48 \mathrm{~mm})$ used. The achieved functional results were evaluated using the Harris Hip Score (HHS) scale.

Results: When assessing long-term results, the average score on the HHS scale significantly increased. During the first year after surgery, there was a 2.2-fold improvement in functional results. There was inconsistent creaking in the implanted joint in only $2.6 \%$ of cases with a CoC friction pair with a diameter of $44 \mathrm{~mm}$.

\section{Conclusions:}

The $\mathrm{CoC}$ monoblock provides good joint function as perceived by the patient. Acoustic effects, in the form of a minor creaking, did not affect the functional results.

\section{Introduction}

The goal of total hip arthroplasty (THA) is to provide ease to patients with persistent and exhausting pain, improve hip joint mobility, support the ability of the leg and improve quality of life.

Long-term studies on large patient populations and reports based on data from large registers of arthroplasty have indicated the successful functioning of implanted artificial joints for 10 years in $95-97 \%$ of patients and demonstrated high survival rates with a follow-up duration of more than 20-30 years [1], [2], [3], [4]. Durability is the main challenge in any tribological pair, with the aim of minimizing wear and thus avoiding problems with the aseptic loosening of components and osteolysis [5], [6], [7].

Ceramic components for THA have been used for more than 40 years ${ }^{[8]}$. Authors have noted that implantation of a ceramic-on-ceramic (CoC) tribological pair reduces the wear rate of friction surfaces, especially in active patients, and minimizes the amount of debris [9], [10].

D. Hu and colleagues reported the survival rate of a hip prosthetic implant to be $98.9 \%$ over a period of $14-16$ years, even when using thirdgeneration ceramics ${ }^{[11]}$.

S. Colas et al. reported that over the past 5 years in France, approximately 35,000 THA procedures were performed using CoC friction pairs ${ }^{\text {[12] }}$.

In Russia, CoC friction pairs are not widely used. According to Vreden research center, more than $98 \%$ of all implanted endoprostheses used in tribological applications contain polyethylene components ${ }^{[13]}$. The rate of modern ceramic component destruction is less than 1 case per 5000 arthroplasties [14], [15], [16].

In 2010, our colleagues in France began a prospective cohort study including patients who underwent revision surgery using total hip prostheses with various friction pairs. The CoC friction pair was implanted in only 238 of 2107 patients. Researchers found that in 41 cases (17\%) among the 238 patients, the reasons for revision surgery were instability of the implanted acetabular component; in 39 (16\%) and 23 cases $(10 \%)$, the reasons were infection and dislocation of the endoprosthesis, respectively. Osteolysis as the cause of instability was reported only in 4 cases $(2 \%)$ of 238 implantations. A total of 37 revision surgeries were performed due to problems associated with the use of ceramic components (i.e., ceramic fracture $(n=23)$, creaking $(n=6)$, impact $(n=7)$, and incorrect insert positioning $(n=1))$ [17], [16]. In this study, the authors demonstrated good results after using a CoC friction pair. Some researchers have noted that phenomena such as creaking and ceramic fractures remain even after introducing Biolox delta (CeramTec $\mathrm{Gmbh}$ ) arthroplasty and after using large-head prostheses with a head diameter $\geq 36 \mathrm{~mm}^{\text {[18] }}$. For example, creaking as an acoustic effect occurs in $0.5 \%$ to $20 \%$ of cases [19], [20], [21], [22], [23].

Hamilton W.G. et al. predicted that the introduction of Biolox delta ceramics would reduce the risk of ceramic destruction close to zero and provide long-term wear of the friction components [16], [24]. To achieve a better anti-luxation effect, it has been recommended to increase the diameter of the CoC friction pair [25], [26]. In China, at Xianqua Hospital, a randomized controlled trial was conducted to assess whether the use of large ceramic friction pairs provided any benefits in young, active patients. Using the Harris Hip Score (HHS) questionnaire, it was revealed that a large delta ceramic friction pair with a diameter of $36 \mathrm{~mm}$ provided a large range of motion (by an angle of 6.1 degrees) with the same

Page $2 / 12$ 
functional parameters. The authors concluded that the benefits of Biolox delta ceramics were obvious and that they can be recommended for young and active patients, although a long-term study with a duration of 8-10 years would be required ${ }^{\text {[27]. }}$

The use of ceramic components has been associated with few revision interventions. A high level of activity in young patients leads to the accelerated wear of friction components, and thus, implant survival is lower in young patients due to the development of osteolysis and aseptic loosening of the components. After total hip replacement in patients under 50 years of age, approximately $80 \%$ of implants retain normal function after 10 years, and less than $50 \%$ of implants retain normal function after 20 years ${ }^{\text {[28] }}$.

The target patient population for hip implants with a $\mathrm{CoC}$ pair includes young, active people. Increased levels of activity may increase the risk of injuries and falls ${ }^{[29]}$. The average time after implantation until periprosthetic fracture in young people is approximately 5 years, and in older people, it is 10 years. Endoprosthesis luxation is the second most formidable complication. The incidence of luxation is inversely proportional to the head diameter of the prosthetic implant used. According to K. Mai et al., the rate of luxation associated with CoC prosthetic implants in the studied population of 337 patients with an average follow-up of 3.4 years after hip replacement was only $0.6 \%$ [29]. There are only a few possible complications when using a $\mathrm{CoC}$ friction pair. Only scarce data on revision procedures after CoC friction pair implantation are available in national registers. The Swedish registry included 74 cases of complications associated with CoC in 2015 , and the Danish registry included 71 cases of complications with $\mathrm{CoC}^{[30],[31]}$. Thus, the available data and the respective analysis results substantiate the wide practical use of hip arthroplasty using $4^{\text {th }}$-generation CoC tribological pairs. In the available literature, there are practically no reports on the retrospective application of the new ceramic acetabular component-the monoblock Maxera Cup.

Objectives: To evaluate the mid-term results following the use of the monoblock Maxera Cup (Zimmer Biomet) acetabular system of different diameters in cementless THA.

\section{Materials And Methods}

\section{Materials}

In the Moscow City Arthroplasty Center of Botkin City Hospital and Sechenov University during the period from 2012 to 2018 , a total of 103 THAs were performed in 93 patients. The maximum follow-up period was 84 months, and the minimum follow-up period was 15 months. The mean follow-up duration was 4 years ( $49.5 \pm 11.7$ months). The distribution of patients by the number of previously performed operations in different years (during the period from 2012 to 2018), ages, and diagnoses is presented in Table 1. 
Table 1

Distribution of patients by year and number of surgical interventions performed according to the preoperative diagnosis.

\begin{tabular}{|c|c|c|c|c|c|c|c|c|c|c|}
\hline \multirow[t]{2}{*}{ Year } & \multirow{2}{*}{$\begin{array}{l}\text { Number } \\
\text { of } \\
\text { patients }\end{array}$} & \multirow{2}{*}{$\begin{array}{l}\text { Number of } \\
\text { interventions }\end{array}$} & \multirow{2}{*}{$\begin{array}{l}\text { Age } \\
\text { (years) }\end{array}$} & \multicolumn{2}{|l|}{ Sex } & \multicolumn{5}{|c|}{ Diagnosis/number of surgeries } \\
\hline & & & & FF & MM & FHAN & $\begin{array}{l}\text { Unilateral } \\
\text { idiopathic } \\
\text { coxarthrosis }\end{array}$ & $\begin{array}{l}\text { Bilateral } \\
\text { idiopathic } \\
\text { coxarthrosis }\end{array}$ & $\begin{array}{l}\text { Dysplastic } \\
\text { unilateral } \\
\text { coxarthrosis }\end{array}$ & $\begin{array}{l}\text { Femoral neck } \\
\text { pseudarthrosis }\end{array}$ \\
\hline \multirow[t]{3}{*}{2012} & 113 & 15 & $40.2 \pm 5.7$ & 66 & 99 & $\mathrm{~F}-2$ & F-3 & F-1 & 0 & 0 \\
\hline & & & & & & $M-2$ & M-5 & M-0 & & \\
\hline & & & & & & Total 4 & Total 8 & Total 1 & & \\
\hline \multirow[t]{3}{*}{2013} & 111 & 11 & $43.3 \pm 2.1$ & 55 & 66 & $\mathrm{~F}-0$ & $\mathrm{~F}-3$ & 0 & $\mathrm{~F}-1$ & 0 \\
\hline & & & & & & $M-4$ & M-3 & & M-0 & \\
\hline & & & & & & Total 4 & Total 6 & & Total 1 & \\
\hline \multirow[t]{3}{*}{2014} & 111 & 13 & $39.1 \pm 8.7$ & 44 & 55 & $\mathrm{~F}-4$ & $\mathrm{~F}-2$ & $\mathrm{~F}-1$ & 0 & 0 \\
\hline & & & & & & M-0 & M-5 & M-1 & & \\
\hline & & & & & & Total 4 & Total 7 & Total 2 & & \\
\hline \multirow[t]{3}{*}{2015} & 113 & 15 & $42.9 \pm 7.6$ & 66 & 77 & F-3 & $\mathrm{F}-0$ & $\mathrm{~F}-1$ & $\mathrm{~F}-1$ & 0 \\
\hline & & & & & & M-1 & M-5 & M-2 & M-0 & \\
\hline & & & & & & Total 4 & Total 5 & Total 3 & Total 1 & \\
\hline \multirow[t]{3}{*}{2016} & 118 & 19 & $40.8 \pm 5.3$ & 55 & 113 & $\mathrm{~F}-0$ & $\mathrm{~F}-1$ & $\mathrm{~F}-0$ & $\mathrm{~F}-2$ & $\mathrm{~F}-0$ \\
\hline & & & & & & M-2 & M-9 & $M-1$ & M-2 & M-1 \\
\hline & & & & & & Total 2 & Total 10 & Total 1 & Total 4 & Total 1 \\
\hline \multirow[t]{3}{*}{2017} & 118 & 20 & $48.1 \pm 2.1$ & 55 & 113 & 0 & $\mathrm{~F}-2$ & $F-1$ & $\mathrm{~F}-0$ & 0 \\
\hline & & & & & & & $M-12$ & M-2 & $M-1$ & \\
\hline & & & & & & & Total 14 & Total 3 & Total 1 & \\
\hline \multirow[t]{3}{*}{2018} & 99 & 10 & $39.8 \pm 9.1$ & 44 & 55 & 0 & $\mathrm{~F}-0$ & $\mathrm{~F}-1$ & 0 & 0 \\
\hline & & & & & & & M-5 & $M-0$ & & \\
\hline & & & & & & & Total 5 & Total 1 & & \\
\hline \multirow[t]{2}{*}{ Total } & 993 & 103 & $46.7 \pm 12.1$ & 335 & 558 & 18 & 55 & 22 & 7 & 1 \\
\hline & & & & & & surgeries & surgeries & surgeries & surgeries & surgery \\
\hline
\end{tabular}

The large variation in the number of interventions in different years is explained not only by economic issues but also by the difficulty of choosing active people of working age from a cohort of elderly patients. Thirty-five women and 58 men aged 19 to 64 years were surgically treated. The number of treated women in the study was 1.6 times less than that of men. Women of childbearing age (19 to 40 years) predominated, and these individuals also had a high degree of physical activity, which was a determining factor for choosing the CoC friction pair.

Sixty-four patients (68\%) experienced idiopathic coxarthrosis. These patients were of fairly young working age (31 to 64 years; average 46 years) and had previously engaged in amateur and professional sports. Of these, 50 (53.8\%) were men and 16 (17.2\%) were women. In the entire studied population, bilateral THA was performed in 11 patients (11.9\%) experiencing bilateral destruction of the hip joints. Of these, 6 were men (54.5\%) and 5 were women (45.5\%). A total of 18 cases of femoral head aseptic necrosis (FHAN) were registered in our patient population. The sex distribution of those with FHAN was equal. Seven THAs for dysplastic coxarthrosis were performed in 4 women and 3 men. Only 1 patient (1.1\%), aged 60 years, experienced femoral neck pseudoarthrosis, which was the outcome of previous incorrect osteosynthesis for femoral neck fracture. Three patients (women aged 49, 57 and 58 years) with bilateral destruction of the hip joints refused consent to required hip arthroplasty of the second joint.

When performing THA, we sought to maximize the use of large cups depending on a specific condition, and accordingly, we aimed to use largediameter tribological pairs to prevent luxation by the implant itself. The use of a large-diameter friction pair reduces the risk of endoprosthesis luxation due to an increased distance that the femoral neck travels until impingement with the edge of the acetabular component [26], [3]. 
However, it is possible that a large-diameter tribological pair can produce various acoustic noises in the implanted prosthesis. Will it bother the patient? How will tribological pairs with different diameters behave in fairly young, previously active and healthy patients? Accordingly, for observation and evaluation of the results, all 103 THA cases were divided into working groups where different CoC diameters were used: 40 $\mathrm{mm}, 44 \mathrm{~mm}$, and $48 \mathrm{~mm}$. There were 2 exceptions: female patients of small stature, i.e., 149 and $152 \mathrm{~cm}$, with BMls of 13.2 and 14.8 , respectively. The minimum size of the native acetabulum, even after preparation, allowed the implantation of a cup with a ceramic head of a maximum of only $36 \mathrm{~mm}$. A more significant geometric parameter in such a situation is the difference between the diameter of the cup and the size of the endoprosthetic head. We believe that this situation is quite representative, and these 2 patients did not require separate allocation but were included in the group of patients with a 40-mm diameter ceramic head. The general characteristics of the patients are presented in Table 2.

The durations of surgical interventions were similar between groups. The longer intervention duration time in group 3 was due to the thickness of the subcutaneous adipose tissue in the trochanteric region and the time required for its suturing. The higher intraoperative blood loss in group 3 can be explained by the larger diameter of the acetabulum. In the postoperative period, standard drainage was established intraarticularly for 2 days to provide an active aspiration of discharge in $100 \%$ of patients. There was little difference in postoperative blood loss among the 3 groups. Intraoperative and postoperative blood loss in all groups analysed was not critical. Body mass index was comparable in all groups regardless of sex. The time intervals for monitoring patients after surgery were similar.

Table 2

General characteristics of patients with different Maxera Cup CoC diameters.

\begin{tabular}{|c|c|c|c|}
\hline Parameter & Friction pair diameter, 40 mm & Friction pair diameter, 44 mm & Friction pair diameter, $48 \mathrm{~mm}$ \\
\hline Total number of patients, 93 & Males, 13 (22.4\%) & Males, 20 (34.5\%) & Males, 25 (43.1\%) \\
\hline - Males, 58 (62.4\%) & Females, 11 (31.4\%) & Females, 14 (40\%) & Females, 10 (28.6\%) \\
\hline \multicolumn{4}{|l|}{ - Females, 35 (37.6\%) } \\
\hline Total number of interventions, 103 & $31(30.1 \%)$ & $38(36.9 \%)$ & $34(33 \%)$ \\
\hline Patient age (years) & $41.9( \pm 2.1)$ & $49.8( \pm 6.6)$ & $50.8( \pm 3.6)$ \\
\hline Males & $28.7( \pm 2.6)$ & $34.5( \pm 8.7)$ & $32.8( \pm 4.4)$ \\
\hline \multicolumn{4}{|l|}{ Females } \\
\hline \multirow[t]{2}{*}{ BMI } & Males, $23.2( \pm 5.4)$ & Males, $24.1( \pm 9.8)$ & Males, $25.3( \pm 7.6)$ \\
\hline & Females, $20.6( \pm 7.4)$ & Females, $23.3( \pm 6.7)$ & Females, $21.8( \pm 9.8)$ \\
\hline Intervention duration (min) & $83.4( \pm 15.5)$ & $88.7( \pm 14.7)$ & $91.1( \pm 15.6)$ \\
\hline Intraoperative blood loss (ml) & $249.1( \pm 86.7)$ & $292.1( \pm 66.7)$ & $310.5( \pm 74.3)$ \\
\hline Postoperative blood loss (ml) & $420.3( \pm 110.6)$ & $439.9( \pm 116.7)$ & $484.2( \pm 112.4)$ \\
\hline Duration of follow-up (months) & $69.5( \pm 6.5)$ & $71.5( \pm 7.2)$ & $70.4( \pm 4.1)$ \\
\hline
\end{tabular}

All patients underwent a preoperative and postoperative clinical examination of the range of motion. The data obtained were recorded in the HHS protocol. In $100 \%$ of patients, prior to arthroplasty, impaired gait and claudication were noted. Eighty-one patients (87\%) were able to ambulate only with additional support. Of these, 63 patients $(77.8 \%)$ walked with a cane, and 18 patients (22.3\%) walked with crutches. Seventy-four patients (79.6\%) used railings for support when climbing stairs. Only 27 patients (29\%) in the entire cohort could pass at a distance of 2-3 quarters. When wearing socks and shoes, 13 patients (14\%) required outside aid. When moving around the city, only 36 patients (38.7\%) used public transport, and the remaining patients preferred a car with a driver. Only 30 patients (32.3\%) from the cohort of those who had a driver license could independently drive a car. The clinical preoperative examination showed fixed flexion contracture in 78 patients (83.9\%) and fixed adduction in 62 patients (66.7\%). More than 15 degrees of internal rotation during extension was registered in 2 cases (1.94\%). A difference in the length of the lower limbs of more than $1 \mathrm{~cm}$ was registered in 73 patients (78.5\%).

\section{Methods}

The monoblock Maxera Cup (Zimmer Biomet) acetabular system was used in all cases as the acetabular component with 4th -generation ceramic insert Biolox delta ceramics (CeramTec $\mathrm{Gmbh}$ ). The Maxera Cup has large-diameter bearings for Biolox delta or Biolox option femoral heads and ranges in size from 36 to $48 \mathrm{~mm}$. The cup is made of Tivanium titanium alloy of cementless fixation with an internal cone of 18 degrees and a fixed aluminium-zirconium ceramic insert (bearing). The full hemispherical cup design has three sets of paired anti-rotation ribs 
to ensure the stability of the press-fit fixation. The $\mathrm{CoC}$ friction pair provides increased wear resistance and high resistance to destruction, as well as chemical and hydrothermal stability.

Our choice of the Maxera Cup was obvious. It allows a larger diameter of the head to be achieved. The use of a cup with a factory-installed ceramic insert precludes the incorrect positioning of the insert and reduces the duration of the implantation procedure. There is no need to screw the screws into the cup, which also reduces intraoperative time.

We used a fourth-generation $\mathrm{CoC}$ friction pair in all 103 cases. A range of monoblock Maxera Cup sizes was used, where the choice was primarily dependent on the size of the patient's acetabulum, the presence of acetabular cysts, a deficiency at the bone edge, the presence of osteophytes, and the intent to implant the cavity that can provide the largest friction pair size with an increased range of joint motion and antiluxation function. The average size of the implanted endoprosthetic cup was $58 \mathrm{~mm}$ (range $48-64 \mathrm{~cm}$ ).

At the preoperative planning stage, hip joint CT was performed in patients with dysplastic arthrosis, thus revealing the possibility of achieving full acetabular sphericity and acetabular depth when installing the Maxera Cup with minimal bone margin deficiency. Otherwise, the patient was excluded from the study cohort and excluded from the study. These clinical situations required other options for restoring and creating the supporting ability of the acetabulum (multiperforated cups, tantalum devices, reinforcing rings, bone grafting of the defect and others). The use of a Maxera Cup (Zimmer Biomet) in our study was 100\%. We used different femoral components of the endoprosthesis (Zimmer Biomet), as presented in Table 3.

Table 3

Choice of implanted femoral components of the endoprosthesis.

\begin{tabular}{|c|c|c|}
\hline Name of the endoprosthesis stem (Zimmer Biomet) & Clinical diagnosis & $\begin{array}{l}\text { Number used } \\
(n=103)\end{array}$ \\
\hline Fitmore Hip Stem & Idiopathic coxarthrosis, FHAN & $66(64.1 \%)$ \\
\hline CLS Spotorno Stem & Idiopathic coxarthrosis, FHAN & $7(6.8 \%)$ \\
\hline Wagner Cone Prothesis Hip Stem & Dysplastic coxarthrosis, proximal femoral dysplasia & $2(1.9 \%)$ \\
\hline Avenir Hip Stem & Dysplastic coxarthrosis, FHAN, acetabular dysplasia & $17(16.5 \%)$ \\
\hline M/L Taper Hip Prothesis & Idiopathic coxarthrosis, FHAN & $6(5.9 \%)$ \\
\hline Alloclassic Zweymuller Stem & Idiopathic coxarthrosis, FHAN & $5(4.8 \%)$ \\
\hline
\end{tabular}

The choice of hip stem depended on the shape of the medullary canal, bone quality, proximal femoral dysplasia and femoral neck torsion. Considering the prevalence of young patients of working age, we preferred Fitmore proximal fixation stems (66 cases, $64.1 \%)$ not only to achieve osseointegration but also to maximally spare the patient's own proximal femoral bone tissue. In 2 cases of acetabular dysplasia, the Avenir stem was implanted. In 2 cases of proximal femoral dysplasia with a version of the femoral neck, the Wagner conical stem was implanted to allow proper positioning of the endoprosthesis components. In this situation, a preoperative hip joint CT scan was performed. The achieved functional results were evaluated using the Harris Hip Score (HHS) scale, where the sum of 80-100 points indicated a good result, 70-79 points indicated a satisfactory result, and less than 70 points indicated an unsatisfactory result.

Thus, all 103 THAs in 93 patients were divided into 3 groups according to the diameters of the CoC friction pairs used (40, 44, and 48 mm). One hundred percent of the patients were available for examination. The patients were evaluated using the HHS before surgical intervention, at 3 months, 6 months, and 1 year after arthroplasty and subsequently at intervals of $1-3$ years, 3-5 years, and 5-7 years, which allowed us to obtain mid-term results. An X-ray examination was performed before surgery (standard X-ray of the pelvis with two hip joints on one film, damaged hip joint in frontal view and in Lauenstein setup view) and at the time points described above. CT was performed in cases of joint dysplasia.

The data obtained in this study were processed using the statistical software Statistica 10.0 and IBM SPSS Statistics 22.0. We used the Kolmogorov-Smirnov test to statistically analyse the study results to determine the normality of data distribution. Normally distributed continuous variables are presented as the mean $(\mathrm{M}) \pm$ standard deviation (SD). To describe qualitative characteristics, relative (\%) and absolute values were used. Student's t-test was used for the comparative analysis of quantitative parameters (parameters were studied before and after the operation). The chi-square test was used to compare qualitative characteristics.

\section{Results}


We were able to identify, follow-up, and assess all 93 patients who underwent THA using questionnaires and clinical examination methods. A total of $96.7 \%$ of our patients did not require additional support to be able to walk by postoperative months $3-3.5$. By postoperative month 6 , only the 2 surgically treated female patients who experienced bilateral coxarthrosis and refused to continue the staged treatment with second joint arthroplasty on the opposite side continued to use a cane when walking. These patients were satisfied with the functional results achieved and the level of activity.

The clinical postoperative examination performed 6 months after arthroplasty revealed no fixed flexion contracture or fixed adduction in any patient. Less than 10 degrees of internal rotation during leg extension was observed in 17 patients (18.3\%) by month 6 and in 4 patients (4.3\%) by 1 year after surgery. A difference in the length of the extremities greater than $1 \mathrm{~cm}$ was noted in 5 patients (5.4\%). Statistical analysis showed the absence of a statistically significant difference in the functional results before surgery according to the HSS scale between all 3 groups $(p>0.05)$. A statistically significant difference in the HSS scale was obtained when comparing scores prior to surgery and 3 months after surgery within all groups $(\mathrm{p}<0.05)$. However, no significant differences between the groups were obtained at any subsequent follow-up period. The obtained mid-term results are presented in Fig. 1.

The obtained data (reflected in the bar diagrams) indicated good results in all three groups of patients using the monoblock Maxera Cup and various diameters of $\mathrm{CoC}$ pairs in the mid-term postoperative period. When assessing long-term results, the average HHS significantly increased, from 40.10 points (preoperation) to 90.20 points (postoperation) $(p<0.05)$ in the 1 st group, from 41.24 to 89.90 points ( $<<0.05)$ in the $2 n d$ group, and from 41.70 to 91.60 points $(p<0.05)$ in the 3rd group. From preoperation to 1 year postoperation, there was a 2.2 -fold improvement in the functional results in group 1 and a 2.1-fold improvement in groups 2 and 3 , indicating excellent treatment results. Based on literature reports and the experience of foreign colleagues, including data from a pool of 500 THA cases, Table 4 was compiled; the table lists potential THA complications, including those obtained during our study, and highlights possible specific complications associated with CoC pairs ${ }^{\text {[32] }}$

Table 4

Observed complications of total hip arthroplasty using the Maxera Cup (Zimmer Biomet). CoC pairs of Biolox delta (CeramTec Gmbh) with 40-, 44-, and 48-mm diameters were used.

\begin{tabular}{|c|c|c|c|}
\hline $\begin{array}{l}\text { Complications of total hip } \\
\text { arthroplasty }\end{array}$ & $\begin{array}{l}\text { Cup insert and } 40-\mathrm{mm} \text { head } \\
\text { diameter } \\
(n=31)\end{array}$ & $\begin{array}{l}\text { Cup insert and 44-mm head } \\
\text { diameter } \\
(n=38)\end{array}$ & $\begin{array}{l}\text { Cup insert and 48-mm head } \\
\text { diameter } \\
(n=34)\end{array}$ \\
\hline Soft tissue haematoma & 0 & $1(2.6 \%)$ & $2(5.9 \%)$ \\
\hline Endoprosthesis luxation & 0 & 0 & 0 \\
\hline Heterotypic ossification & 0 & 0 & 0 \\
\hline $\begin{array}{l}\text { Osteolysis/aseptic loosening of } \\
\text { components }\end{array}$ & 0 & 0 & 0 \\
\hline $\begin{array}{l}\text { Deep periprosthetic infection, septic } \\
\text { loosening }\end{array}$ & 0 & 0 & 0 \\
\hline Periprosthetic fracture & 0 & 0 & 0 \\
\hline Revision arthroplasty & 0 & 0 & 0 \\
\hline \multicolumn{4}{|c|}{ Specific complications after using a ceramic-on-ceramic tribological pair } \\
\hline Monoblock insert fracture & 0 & 0 & 0 \\
\hline Acoustic effect: knocking & 0 & 0 & 0 \\
\hline $\begin{array}{l}\text { Acoustic effect: } \\
\text { creaking }\end{array}$ & 0 & $1(2.6 \%)$ & 0 \\
\hline
\end{tabular}

\section{Discussion}

A prospective analysis of the complications registered in our study demonstrated minimal complications. Postoperative soft tissue haematomas, with partial suture failure and the formation of a cavity in the subcutaneous fatty tissue that required excision of the defect, and wound debridement with subsequent closure were noted in 3 patients (2.9\%), all of whom were females with BMls of 30-31.2 and received large friction pairs. The low BMI in all patients was offset by an anatomical feature-the thickness of the subcutaneous fat in the trochanteric region was 11-12.5 cm. Healing was achieved in all cases. Luxation of the endoprosthesis is the most frequent early complication after THA and one of the most common causes of early revision ${ }^{[14]}$. According to the 2018 Australian registry, $21.1 \%$ of complications among all revision 
surgeries after THA were caused by luxation of the endoprostheses. Luxation of the endoprosthesis takes second place after aseptic instability [33].

Men who were fairly young with high previous levels of activity predominated in our study. Therefore, they had the highest risk of falls and endoprosthesis luxation resulting from injuries, inconsistent with the study performed by R.M. Meek et al., who analysed a large amount of clinical material and did not establish a sex effect on the incidence of luxation ${ }^{[34]}$.

According to Russian orthopaedists, endoprostheses with solid friction pairs are less prone to luxation than those with other friction pairs. Better wettability, as well as the ability for self-polishing and bedding, provide greater stability of the joints when using them ${ }^{[26]}$. Male patients predominated in our clinical study, and we did not register any cases of endoprosthesis luxation during the entire mid-term follow-up period despite the young working ages of patients and the sporting components of their lives. There are essentially no publications in the scientific literature on the medium-term results of use of the monoblock Maxera Cup, allowing comparisons with data on the use of a similar tribological pair. Our results are similar to those reported by J.A. D'Antonio et al., who performed 475 THAs using implants with a similar friction pair. The follow-up period after surgery ranged from 4 to 9 years. These authors also did not observe formidable complications such as luxation [35]. The work and experience of 30 years of practice in our arthroplasty centre show that to achieve the best anti-luxation effect, it is advisable to increase the diameter of the $\mathrm{CoC}$ friction pair ${ }^{[25]}$. To minimize the risk of luxation, we sought to install CoC pairs with a large diameter. We fully agree with Amstutz H.C. and other authors who advocate the use of large-diameter friction pairs, which provide a great range of motion and increase the so-called "jumping distance", that is, the distance that the head must travel before luxation occurs [36], [37].

One of the unpleasant concomitant effects after arthroplasty using CoC pairs is possible acoustic phenomena in the area that arthroplasty was performed. It has been noted that these acoustic phenomena are more often observed in younger, taller and heavier patients, as well as in more active patients [38], [39], [40], [41].

It is believed that creaking in an audible frequency range occurs due to forced vibration due to the action of the friction force and resonant frequencies of the implant components. Herewith, the natural resonance frequency of ceramic components is either at the very upper end of the human audible frequency range or outside of this frequency range [41], [42], [43]. Professor William L. Walter emphasized that creaking phenomena can be present even with the correct alignment secured during implant placement and in the absence of contact between the endoprosthesis neck and the cup [44], [43].

In 2018, the results of a joint study by endoprosthetic specialists from Australia and Canada based on 276 operations using a monoblock acetabular component Maxera Cup with large CoC friction pairs were published. The follow-up period after implantation averaged 67 months. No cases of luxation were registered by these colleagues. However, the frequency of the creaking phenomenon was $23 \%$. Creaking was associated with larger head diameters, younger patient age, and higher activity scores. Interestingly, the creaking that was present did not affect patient satisfaction or functional outcomes. All patients with "creaking joints" were satisfied with the arthroplasty results. The authors concluded that the monoblock component of the Maxera Cup can provide long-term prosthesis survival with unlimited patient activity; that is, no instability occurs ${ }^{[45]}$. Another researcher from Australia noted that after THA in 206 cases where CoC pairs were used, the frequency of creaking increased from $7.3 \%$ during postoperative year 2 to $17.4 \%$ by postoperative year 5 . However, the authors did not note the relationship between the occurrence of creaking and patient age, height, or weight or diameter of the endoprosthesis head. It was noted that creaking more often occurs in females, but for some reason, the question remains unaddressed. No destruction of the ceramic component was registered in the previous study ${ }^{[46]}$.

In our study, inconsistent creaking in the implanted joint was noted in only one patient aged 43 years with a CoC friction pair with a diameter of $44 \mathrm{~mm}$ ( $2.6 \%$ of the total number of friction pairs with this diameter and $0.97 \%$ of the total number of surgical interventions). The patient noted the occurrence of creaking at postoperative month 8 . The acoustic effect is still present; however, it does not affect the functional results and has not progressed over the entire observation period of 42 months after endoprosthesis implantation. In his Practical Guide for Physicians, Walter W.L. and co-authors clearly stated the surgeon's actions algorithm in cases of implanted "noisy hip joints" [47]. Given the complete absence of pain, the inconsistency of creaking, the absence of discomfort and correct stable X-ray positioning of the total endoprosthesis, there were no indications for revision surgery. The patient was fully satisfied with the functional results. After arthroplasty, complaints of pain were noted in only two patients (2.2\%). The pain syndrome was of minor intensity. The pain was not consistent in nature; it was associated with increased stress and with hip-spine syndrome, and it was relieved by nonsteroidal anti-inflammatory drugs (NSAIDs) ${ }^{\text {[48] }}$. We did not observe any complications associated with aseptic or septic loosening of the components either clinically or radiologically during the 7-year follow-up period after surgery (the average follow-up duration was 4 years or 49.5 months) in the entire patient population.

\section{Conclusion}


Use of the monoblock Maxera Cup allows us to expect an increase in the life cycle of the endoprosthesis. CoC pairs provide good joint function and good perception by the patient. An acoustic effect in the form of minor creaking, which was noted in $2.6 \%$ of cases, did not affect the functional results.

During our study, there was no significant difference in the functional results between the 3 study groups. The peak of improvement became obvious by the 3rd month after surgical intervention. Taking into account the high wear resistance of a CoC friction pair, we can expect an increased number of joint motion cycles, which certainly is of great importance for active, working patients.

There was a limitation to our work. We did not compare patients in whom the monoblock Maxera Cup was implanted to those in whom modular CoC components were implanted. Our research will be continued. After increasing the number of cases, it will be of interest to compare our cohort with a cohort of patients with modular ceramic components. Long-term prospective observational studies and further research are required.

\section{Declarations}

Conflict of interest. The authors have no conflict of interest to report. No specific funding was received. Each author certifies that he has no commercial associations that might pose a conflict of interest in connection with the submitted article.

Ethical approval. All studies to have been performed in accordance with the ethical standards in the 1964 Declaration of Helsinki. All studies were carried out in accordance with relevant regulations of the US Health Insurance Portability and Accountability Act (HIPAA). This study was approved by I.M.Sechenov First State Moscow Medical University ethics committee.

The informed consent was obtained from all subjects, all of them were older than 18.

Funding: There is no funding source.

\section{References}

1. Tikhilov R.M., Shubnyakov M.I., Boyarov A.A. , Denisov A.O. , Shubnyakov I.I. Impact of Various Factors on the Polyethylene Wear Rate in Total Hip Arthroplasty Traumatology and orthopedics of Russia 2018 Vol. 24, N 1, P18-28 DOI: 10.21823/2311-2905-2018-24-1-18-28.

2. Petsatodis G.E., Papadopoulos P.P., Papavasiliou K.A.,Hatzokos I.G., Agathangelidis F.G., Christodoulou A.G.Primary cementless total hip arthroplasty with an alumina ceramic-on-ceramic bearing: results after a minimum of twenty years of follow-up. J Bone Joint Surg Am.2010;92(3):639-644. doi : 10.2106/JBJS.H.01829.

3. Stefl M.D., Callaghan J.J., Liu S.S., Pedersen D.R., Goetz D.D., Johnston R.C. Primary cementless acetabular fixation at a minimum of twenty years of follow-up: a concise update of a previous report. J Bone Joint Surg Am.2012;94(3):234-239. doi : 10.2106/JBJS.K.00237.

4. Warth L.C., Callaghan J.J., Liu S.S., Klaassen A.L.,Goetz D.D., Johnston R.C. Thirty-five-year results after Charnley total hip arthroplasty in patients less than fifty years old. A concise follow-up of previous reports. J BoneJoint Surg Am. 2014;96(21):1814-1819.doi: 10.2106/JBJS.M.01573.

5. Kinkel S., Wollmerstedt N., Kleinhans J.A., Hendrich C., Heisel C. Patient activity after total hip arthroplasty declines with advancing age. Clin Orthop Relat Res.2009;467(8):2053-2058.doi : 10.1007/s11999-009-0756-3.

6. Pokorný D., Slouf M., Veselý F., Fulín P., Jahoda D.,Sosna A. Distribution of UHMWPE wear particles in periprosthetic tissues of total hip replacements. Acta Chir Orthop Traumatol Cech. 2010;77(2):87-92.

7. Schmalzried T.P., Shepherd E.F., Dorey F.J., Jackson W.O., dela Rosa M., Fa'vae F. et al. Wear is a function of use, not time. Clin Orthop Relat Res. 2000;(381):36-46.

8. Boutin P. Total arthroplasty of the hip by fritted aluminum prosthesis. Experimental study and 1st clinical applications. Orthop Traumatol Surg Res. 2014;100:15-21.

9. Lerouge S, Huk O, Yahia L, Witvoet J, Sedel L. Ceramic-ceramic and metal-polyethylene total hip replacements: comparison of pseudomembranes after loosening. J Bone Joint Surg Br. 1997;79:135-139.

10. Rousseau M.A., Le Mouel S., Goutallier D., Van Driessche S. Long-term results of alumina-on-alumina total hip arthroplasty. Rev Chir Orthop Reparatrice Appar Mot. 2004;90:741-748.

11. Hu D., Tie K., Yang X., Tan Y., Alaidaros M., Chen L. Comparison of ceramic-on-ceramic and metal-on-polyethylene bearing surfaces in total hip arthroplasty:meta-analyses of randomized controlled studies. J Orthop Surg Res. 2015;10:22. DOI: 10.1186/s13018-015-0163-2. 
12. Colas S., Collin C., Piriou P., Zureik M., Association between total hip replacement characteristics and 3-year prosthetic survivorship: a population-based study. JAMA Surg. 2015;150:979-988.

13. Shubnyakov I.I., Tikhilov R.M., Nikolaev N.S., Grigoricheva L.G., Ovsyankin A.V., Cherny A.Z., Drozdova P.V., Denisov A.O., Veber E.V., Kuz'mina I.V. Epidemiology of primary hip arthroplasty: report from register of Vreden Russian Research Institute of Traumatology and Orthopedics. Travmatologiya i ortopediya Rossii [Traumatology and Orthopedics of Russia]. 2017;23(2):81-101.(in Russian).DOI:10.21823/2311-2905-2017-23-2-81-101.

14. Allain J., Roudot-Thoraval F., Delecrin J., Anract P., Migaud H., Goutallier D. Revision total hip arthroplasty performed after fracture of a ceramic femoral head. A multicenter survivorship study. J Bone Joint Surg Am. 2003;85:825-830.

15. Kuo F-C, Liu H-C, Chen W-S, Wang J.W. Ceramic-on-ceramic total hip arthroplasty: incidence and risk factors of bearing surface- related noises in 125 patients. Orthopedics. 2012;35:e1581- 1585.

16. Reina N, Delaunay C, Chiron P, Ramdane N, Hamadouche M; SoFCOT. Infection as a cause of primary total hip arthroplasty revision and its predictive factors. Orthop Traumatol Surg Res.2013;99:555-561.

17. Delaunay C, Hamadouche M, Girard J, Duhamel A, SoFCOT Group. What are the causes for failures of primary hip arthroplasties in France? Clin Orthop Relat Res. 2013;471:3863-3869.

18. Migaud H., Putman S., Kern G., Isida R., Girard J., Ramdane N., Delaunay C.P., Hamadouche M. The SoFCOT Study Group Do the Reasons for Ceramic-on-ceramic Revisions Differ From Other Bearings in Total Hip Arthroplasty? Clin Orthop Relat Res (2016) 474: D0I 10.1007/s11999-016-4917-x. Volume 474, Number 10, October 2016 p. 2190-2199

19. Baek S.H., Kim W.K., Kim J.Y., Kim S.Y. Do alumina matrix composite bearings decrease hip noises and bearing fractures at a minimum of 5 years after THA? Clin Orthop Relat Res. 2015;473:3796-3802.

20. Chevillotte C., Trousdale R.T., An K.N., Padgett D., Wright T. Retrieval analysis of squeaking ceramic implants: are there related specific features? Orthop Traumatol Surg Res. 2012;98:281-287.

21. Cogan A., Nizard R., Sedel L. Occurrence of noise in alumina-on alumina total hip arthroplasty. A survey on 284 consecutive hips. Orthop Traumatol Surg Res. 2011;97:206-210.

22. Keurentjes J.C., Kuipers R.M., Wever D.J., Schreurs B.W. High incidence of squeaking in THAs with alumina ceramic-on-ceramic bearings. Clin Orthop Relat Res. 2008;466:1438-1443.

23. Porat M., Parvizi J., Sharkey P.F, Berend K.R., Lombardi A.V. Jr., Barrack R.L. Causes of failure of ceramic-on-ceramic and metal-on-metal hip arthroplasties. Clin Orthop Relat Res. 2012;470:382-387.

24. Hamilton W.G., McAuley J.P., Dennis D.A., Murphy J.A., Blumenfeld T.J., Politi J. THA with Delta ceramic on ceramic: results of a multicenter investigational device exemption trial. Clin Orthop Relat Res. 2010;468:358-366. doi: 10.1007/s11999-009-1091-4.

25. Murylev V.Y., Kavalersky G.M., Terentiev D.I., Rukin Y.A., Elizarov P.M., Muzychenkov A.V. Five-year outcomes of ceramic-on-ceramic and ceramic-on-polyethylene bearings in hip joint replacement. Traumatology and orthopedics of Russia.2017;23(1):89-97.(In Russ.) https://doi.org/10.21823/2311-2905-2017-23-1-89-97 (31)

26. Molodov M.A., Danilyak V.V., Kluchevsky V.V., Gilfanov S.I., Kluchevsky V.V., Vergay A.A. Risk factors for total hip arthroplasty dislocations. Traumatology and orthopedics of Russia. 2013;(2):23-30. (In Russ.) https://doi.org/10.21823/2311-2905-2013-0-2-65-71.

27. Cai P., Hu Y.,Xie J. Large-diameter Delta ceramic-on-ceramic versus common-sized ceramic-on-polyethylene bearings in THA. J. Orthopedics.2012,Sep.35(1307-1313.).

28. Heisel C., Silva M., Schmalzried T.P. 2007 Bearing surface options for total hip replacement in young patients. Inst.Course.Lect.2004;5364965.

29. Mai K., Hardwick M.E., Walker R.H., Copp S.N., Ezzet, K.A., Colwell C.A. Early dislocation rate in ceramic-on ceramic total hip arthroplasty. HSS J. 2008; 4(1):10-13.

30. The Swedish Hip Arthroplasty Register. Annual Report 2013. Available at: http://www.shpr.se/Libraries/Documents/Annual Report_201304-1_1.sflb.ashx. Accessed March 2016.

31. Varnum C., Pedersen A.B., Kjærsgaard-Andersen P., Overgaard S. Comparison of the risk of revision in cementless total hip arthroplasty with ceramic-on-ceramic and metal-on-polyethylene bearings. Acta Orthop. 2015; 86:477-84.

32. Almaawi A., Deny A., Roy A., Masse V., Lavigne M.,Vendittoli P.A.Early results of 500 Maxera monoblock acetabular component with a large ceramic bearings at two years follow-up.Orthopaedic Proceedings ,2018vol.98- B, No.supp-20.

33. Australian Orthopaedic Association National Joint Replacemrnt Registry (AOANJRR). Hip, Knee \& Shoulder Arthroplasty :2018.Annual Report. Adelaide: AOA,2018.Available from: https: //aoanjrr.sahmri.com/annual-reports-2018.

34. Meek R.M., Allan D.B., McPhillips G., Kerr L., Howie C.R. Late dislocation after total hip arthroplasty. Clin. Med. Res. 2008; 6(1):17-23. 
35. D’Antonio J.A., Capello W.N., Manley M.T., Naughton M., Sutton K. A titanium-encased alumina ceramic bearing for total hip arthroplasty: 3to 5-year results.Clin. Orthop. Relat. Res. 2005;441:151-158.

36. Lombardi A.V.Jr, Skeels M.D., Berend K.R., Adams J.B., Franchi O.J. Do large heads enhance stability and restore native anatomy in primary total hip arthroplasty. Clin Orthop Relat Res. 2011;469:1547-1553. doi: 10.1007/s11999-010-1605-0.

37. .Von Knoch M., Berry D.J., Harmsen W.S., Morrey B.F. Late dislocation after total hip arthroplasty. J Bone Joint Surg Am. 2002;84$\mathrm{A}(11): 1949-1953$.

38. Baek S.H., Kim S.Y. Cementless total hip arthroplasty with alumina bearings in patients younger than fifty with femoral head osteonecrosis. J Bone Joint Surg Am . 2008, 90:1314-1320.

39. Haq R.U., Park K.S., Seon J.K., Yoon T.R. Squeaking after third-generation ceramic-on-ceramic total hip arthroplasty. J. Arthroplasty 2012, 27(1):909-915.

40. Walter W.L., O'Toole G., Walter W.K., Ellis A., Zicat B.A. Squeaking in ceramic-on-ceramic hips: the importance of acetabular component orientation. J Arthroplasty 2007, 22:496-503.

41. Hothan A., Huber G., Weiss C., Hoffmann N., Morlock M. The influence of component design, bearing clearance and axial load on the squeaking characteristics of ceramic hip articulations. J. Biomech. 2011, 44[5]:837-841.

42. Walter W.L., Waters T.S., Gillies M., Donohoo S., Kurtz S.M., Ranawat A.S., Hozack W.J., Tuke M.A. Squeaking hips. J Bone Joint Surg Am. 2008, 90 [Suppl 4]:102-111.

43. Weiss C., Gdaniec P., Hoffmann N.P., Hothan A., Huber G., Morlock M.M. Squeak in hip endoprosthesis systems: an experimental study and a numerical technique to analyze design variants. Med Eng Phys .2010, 32:604-609.4

44. Walter W.L, Jenabzdadeh R., Reinhardt C. Practical guide for handling noises in hard on hard bearings. Springer Medizin. Springer-Verlag Berlin,Heidelberg, 2015.DOI 10.1007/978-3-642-46027-6.ISBN 978-3-642-46026-9.

45. Blakeney W.G., Beaulieu Y., Puliero B.,Lavigne M.,Roy A., Masse V.,Vendittoli P.A. Excellent results of large-diameter ceramic-on-ceramic bearings in total hip arthroplasty: Is Squeaking Related to head size? Bone Joint J. 2018,Nov100-B(11):1434-1441.

46. Goldhofer M.I., Munir S., Levy Y.D.,WalterW.L.Zicat B.,Walter W.L. Increase in Benign Squeaking Rate of Five-Year-Follow-up: Results of a Large Diametr Ceramic-on ceramic Bearing in total hip Arthroplasty. J.Arthroplasty,2018 Apr 33(4):1210-1214

47. Amstutz H.C., Le Duff M.J., Beaule P.E. Prevention and treatment of dislocation after total hip replacement using large diameter balls. Clin Orthop Relat Res.2004;(429):108-116.

48. Reina N, Delaunay C, Chiron P, Ramdane N, Hamadouche M; SoFCOT. Infection as a cause of primary total hip arthroplasty revision and its predictive factors. Orthop Traumatol Surg Res.2013;99:555-561

\section{Figures}




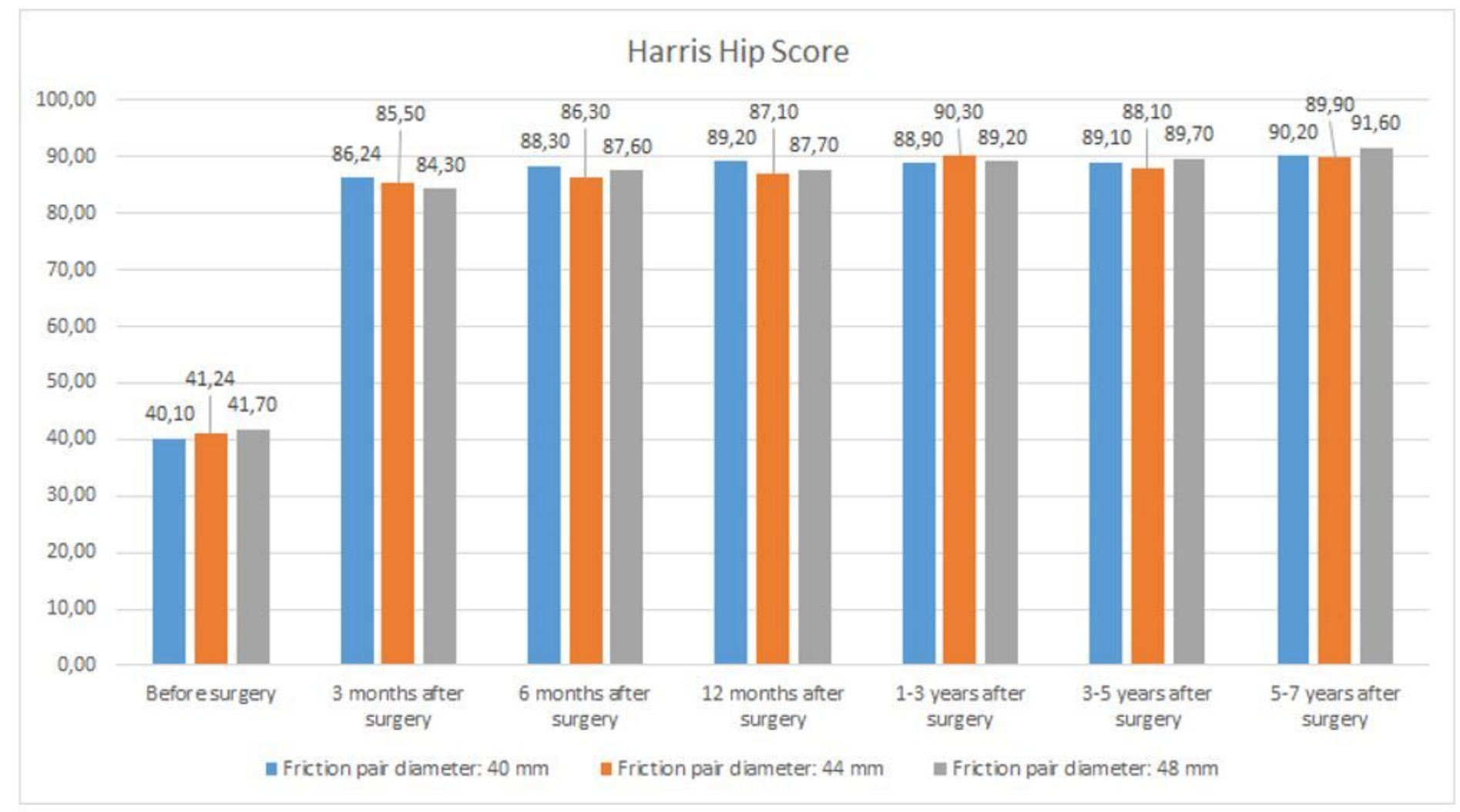

\section{Figure 1}

Functional results according to the HHS scale for total hip arthroplasty before and after surgery. Acetabular system Maxera Cup (Zimmer Biomet). 